\title{
Focos das pesquisas publicadas na CNMEM: Modelagem Matemática e GeoGebra
}

\author{
Focuses of research published in CNMEM: Mathematical Modeling and \\ GeoGebra
}

\author{
Jorge Ricardo Marques Correia \\ Wellington Piveta Oliveira
}

\begin{abstract}
Resumo: Essa pesquisa é fruto do projeto de Iniciação Científica, ainda em desenvolvimento, sobre Modelagem Matemática e o GeoGebra. Com objetivo de responder Que focos das produções em Modelagem Matemática que mencionam o GeoGebra se revelam dos anais da CNMEM (2003-2019)?, a pesquisa interrogou as produções publicadas na Conferência Nacional sobre Modelagem na Educação Matemática (CNMEM), que mencionaram o GeoGebra. Após a seleção das produções, foram realizadas leituras sucessivas dos resumos, possibilitando estabelecer sínteses sobre seus objetivos. A aproximação temática entre esses objetivos permitiu uma convergência, favorecendo à constituição de três núcleos: Modelagem Matemática e GeoGebra na formação de professores; Aspectos da Modelagem Matemática com GeoGebra; Atividades de Modelagem Matemática e GeoGebra. Os resultados sustentam que as produções possuem objetos de investigação distintos, sugerem a emergência de saberes pedagógicos,
\end{abstract} técnicos e matemáticos, bem como despertam reflexões em (jovens) pesquisadores.

Palavras-chave: CNMEM. GeoGebra. Modelagem Matemática. Educação Matemática. Licenciatura em Matemática, na modalidade à distância, da Universidade Cesumar (UniCesumar). Professor do Colégio Municipal Florestal, em Nova Canaã. Bahia, Brasil.

iD orcid.org/0000-0002-6803-0877 $\bowtie$ jrmcorreia10@gmail.com

Abstract: This research is the result of the project of Scientific Initiation still under development, on Mathematical Modeling and GeoGebra. In order to answer: What focuses of the productions in Mathematical Modeling that mention GeoGebra, reveal themselves from the annals of CNMEM (2003-2019)?, the research questioned the productions published in the National Conference on Modeling in Mathematics Education - CNMEM, which mentioned GeoGebra. After the selection of the productions, successive readings of the abstracts were performed, making it possible to establish summaries about their objectives. The thematic approximation between these objectives allowed a convergence, favoring the constitution of three nuclei:

Wellington Piveta Oliveira Doutor em Educação para a Ciência e a Matemática. Professor da Universidade Cesumar (UniCesumar), em Maringá. Paraná, Brasil.

iD orcid.org/0000-0002-3840-1972

$\triangle$ wellington.oliveira@unicesumar.edu.br

Recebido em 11/06/2020 Aceito em 12/07/2020 Publicado em 25/07/2020 Mathematical Modeling and GeoGebra in teacher education; Aspects of Mathematical Modeling with GeoGebra; Activities of Mathematical Modeling and GeoGebra. The results support that the productions have different research objects, suggest the emergence of pedagogical, technical and mathematical knowledge, as well as arouse reflections in (young) researchers.

Keywords: CNMEM. GeoGebra. Mathematical Modeling. Mathematics Education. 


\section{Considerações iniciais}

O ensino e a aprendizagem de Matemática têm chamado a atenção de estudiosos e pesquisadores há algumas décadas. Esse argumento pode ser confirmado por meio dos inúmeros estudos e publicações sobre a Educação Matemática, uma área que, em todo o mundo, tem possibilitado reflexões tanto sobre métodos e metodologias de ensino, quanto no sentido de promover uma aprendizagem com significado para os alunos, extrapolando os muros escolares na direção de uma formação crítica, social e libertadora.

O parágrafo precedente revela um pouco da trajetória do primeiro autor do texto, quando o contato com o ambiente educacional despertou outras novas reflexões no processo formativo, sendo definidor de escolhas. Explicitando um pouco dessa trajetória com o objetivo de situar os motivos que nos levaram à realização desta pesquisa, os parágrafos seguintes encontram-se na primeira pessoa do singular, fazendo referência à trajetória do primeiro autor.

O meu contato com a Matemática, a Modelagem e a Tecnologia, foi iniciado na década de 90, quando concluí o curso Técnico em Processamento de Dados e na mesma década ingressei no curso de bacharelado em Matemática, ambos na cidade de Salvador (BA). A ideia inicial de me tornar bacharel em Matemática era ampliar o conhecimento em Matemática para, no futuro, tornarme um analista de sistemas. 0 curso de Matemática tinha ênfase em informática, o que despertou ainda mais o meu interesse. Ao longo dos anos, pude aproximar-me dos estudos em Matemática com informática, por meio do contato e uso de softwares matemáticos como Maple, Winplot (versão para DOS) e o Cabri. Naquele período, o GeoGebra ainda não havia surgido.

Estudar Matemática com o software Maple teve um significado especial e foi por meio de explorações com ele que um despertar para a licenciatura passou a ser um interesse emergente. Naquele contexto, realizei um estágio em uma escola pública da capital baiana e, diante da experiência e de comentários dos professores da escola, como "Os alunos gostam das suas aulas, você tem habilidade pra lecionar", foi que me dei conta do mundo da Educação como professor de Matemática, deixando a ideia de ser analista de sistemas para segundo plano.

Pouco tempo depois, após a colação de grau de bacharel em Matemática, o início como professor de Matemática efetivo em um município baiano, possibilitou utilizar a tecnologia para 0 aprendizado dos alunos. Tentando desenvolver um trabalho dentro das condições contextuais e, na busca por diferentes estratégias, pude conhecer outros modos de conduzir as práticas que se mostraram tão relevantes quanto àquelas articuladas às tecnologias. Refiro-me à Modelagem 
Matemática1.

Diante desse repertório de possibilidades de práticas do qual tenho me deparado em todos esses anos, senti a necessidade de retornar aos bancos acadêmicos para cursar a Licenciatura em Matemática com objetivo de aperfeiçoar a minha prática como professor de Matemática, mediante o conhecimento teórico-prático. Na oportunidade, ingressei no Programa de Iniciação Científica, pesquisando sobre as relações entre GeoGebra e Modelagem, sob a orientação do segundo autor desse texto.

Após uma breve apresentação dos interesses particulares em investigar sobre esse tema, retomamos o texto na primeira pessoa do plural. As motivações que nos levaram à constituição dessa pesquisa decorrem, portanto, do trabalho em parceria no desenvolvimento de um projeto de Iniciação Científica. No projeto, ainda em desenvolvimento, procuramos estreitar a relação entre Modelagem e GeoGebra, pois além de uma motivação particular o empreendimento de trabalhos como esse pode despertar múltiplos interesses, desde uma aproximação com a atitude de pesquisa ao empreendimento de práticas pedagógicas.

Entendemos que ao buscarmos pelos focos de produções que relacionam de algum modo a Modelagem e o GeoGebra nas publicações da CNMEM, pode despertar o interesse pela investigação de novos temas de pesquisa. Dito de outro modo, situar os focos pode favorecer 0 empreendimento de novas pesquisas, pois ao contribuir com um mapeamento dos focos das produções é possível que forneçamos um panorama da produção sobre o tema no contexto da CNMEM e, com isso, ampliarmos as experiências de ensino, bem como apontar possíveis especulações temáticas que poderão ser investigadas.

Pesquisas dessa natureza, como já indicado por Romanowski e Ens (2006), podem ser consideradas do tipo estado do conhecimento e tendem a nos revelar a trajetória de um tema investigado por uma comunidade científica. Do mesmo modo, pode fornecer indícios de elementos estruturantes sobre esse tema, levando a sua permanência e extensão, como é o caso da própria área de Modelagem apontado por Tambarussi e Klüber (2014).

Nesse sentido, com o objetivo de subsidiar essas e outras reflexões, sentimos a necessidade de conhecer as produções sobre Modelagem que fazem menção ao GeoGebra e compreendemos que um dos lócus de manifestação dessas produções sobre Modelagem é a

\footnotetext{
1 Usaremos o termo "Modelagem" como referência à Modelagem Matemática na Educação Matemática.
} 
Conferência Nacional sobre Modelagem na Educação Matemática (CNMEM), um evento específico da área de Modelagem. Por essa razão, apresentamos essa pesquisa de cunho exploratório, em que investigamos os focos das produções publicadas nos anais da CNMEM, à luz da interrogação Que focos das produções em Modelagem Matemática que mencionam o GeoGebra, se revelam dos anais da CNMEM (2003-2019)?

Com a finalidade de apresentarmos a estrutura desse texto, além dessas Considerações iniciais que expressam a motivação e a relevância desta produção, na sequência apresentaremos algumas reflexões sobre a Modelagem Matemática e o software GeoGebra. Posteriormente, na seção Aspectos metodológicos da pesquisa, o leitor conhecerá o modo pelo qual se desenvolveu o trabalho de pesquisa, desde a reunião das produções à constituição de núcleos que congregaram os focos das produções analisadas. Na seção, Descrições e reflexões, apresentaremos sobre o que versaram os núcleos e possíveis resultados desta pesquisa à luz da interrogação. E, pôr fim, na seção Considerações finais, refletiremos sobre aspectos dirigidos à pesquisa que vão além dela, com o objetivo de não encerrar as discussões, mas de levantar outras possibilidades de investigação.

Apresentadas as motivações, a interrogação e a organização que nos conduziu ao desenvolvimento dessa pesquisa, na próxima seção apresentaremos algumas compreensões sobre a Modelagem e o GeoGebra.

\section{Modelagem Matemática e o software GeoGebra}

As pesquisas sobre Educação Matemática não apresentam soluções para desenvolver 0 ensino e aprendizagem, mas nos trazem reflexões sobre as teorias e práticas que, por sua vez, têm despertado novos olhares para educarmos por meio da Matemática. Entre os diferentes modos para esse despertar, uma discussão sobre Modelagem começou a ocupar os pensamentos, as ações e as reflexões dos professores e pesquisadores desse campo científico e profissional e, do mesmo modo, a inserção do uso de tecnologias.

Biembengut (2009) explicita que o termo "modelagem matemática" como processo para descrever, formular, modelar e resolver uma situação-problema de alguma área do conhecimento encontra-se já no início do século XX na literatura de Engenharia e Ciências Econômicas, por exemplo. Compreendemos que ao longo dos anos, os estudos sobre ela têm sido expressivos, assim como chamado a atenção de pesquisadores no Brasil. 


\begin{abstract}
O debate sobre modelagem e aplicações na Educação Matemática no cenário internacional ocorre, em especial, na década de 1960, com um movimento chamado "utilitarista", definido como aplicação prática dos conhecimentos matemáticos para a ciência e a sociedade que impulsionou a formação de grupos de pesquisadores sobre o tema. No Brasil acredita-se que os estudos sobre a modelagem matemática iniciaram na segunda metade da década de 70 e desde então se tornou tema para muitas pesquisas científicas no país (BIEMBENGUT, 2009, p. 8).
\end{abstract}

Conforme a autora, a Modelagem se apresentava de forma consolidada no cenário internacional, entretanto, no Brasil as pesquisas ganharam força a partir de 1990. Com um aumento significativo de práticas e pesquisas, nesse caminho, foi criada uma comunidade de pesquisadores (BARBOSA, 2007), que identificou a necessidade de partilhar suas pesquisas por meio de eventos direcionados, intencionando o aprofundamento e o enriquecimento das discussões e debates. Nesse sentido é que uma conferência foi idealizada e recebeu o nome de CNMEM. Ela ocorre a cada dois anos, desde a sua primeira edição ocorrida em 1999.

Desde então, o próprio movimento de constituição dessa comunidade deu abertura para que diferentes concepções sobre Modelagem fossem compartilhadas na literatura. Compreendemos que a essência da Modelagem está na problematização e na investigação de um tema definido, em que se utiliza de noções ou conceitos matemáticos, com vistas à elaboração de uma solução que pode ser interpretada como uma representação de um fenômeno inerente ao tema escolhido. Para isso, ocorre um processo de simplificação da situação e mediante a uma análise e interpretação matemática dessa situação, desenvolve-se um modelo, isto é, algo que represente a situação em estudo, permitindo descrever, analisar ou fazer previsões (MEYER, CALDEIRA e MALHEIROS, 2011).

Essa não é a única e nem a mais ampla compreensão sobre Modelagem. Existem outros modos de compreendê-la que se desvelam em diferentes concepções. Dentre elas, citamos a Modelagem como metodologia de ensino, que pode ser entendida como "um conjunto de procedimentos cujo objetivo é construir um paralelo para tentar explicar matematicamente os fenômenos que o homem vive no seu cotidiano, ajudando-o a fazer predições e a tomar decisões" (BURAK, 1992, p. 21). Como metodologia, existe uma "interação entre professor-aluno-ambiente" (KLÜBER e BURAK, 2008, p. 22), em que o aluno é o sujeito que, com a mediação do professor, mobiliza conhecimentos com base nas informações presentes no ambiente - fonte de informações. Uma atividade orientada por esse modelo possibilita uma autonomia dos alunos, de modo que possam desenvolver senso crítico e sejam capazes de refletir e tomar decisões sobre as circunstâncias da vida cotidiana (KLÜBER e BURAK, 2008). 
Outra concepção se assenta na compreensão da Modelagem como um ambiente de aprendizagem, em que a "atitude de modelar" consiste numa espécie de convite aos estudantes. Nesse sentido, "modelagem é um ambiente de aprendizagem no qual os alunos são convidados a indagar e/ou investigar, por meio da matemática, situações oriundas de outras áreas da realidade" (BARBOSA, 2001, p. 6). De acordo com o autor supracitado, uma atividade de modelagem pode ser orientada por alguns casos, que o autor denomina como regiões de possibilidades para a prática com Modelagem. Segundo Barbosa (2001), do Caso 1 ao Caso 3 ocorre, gradativamente, uma maior participação dos alunos desde o envolvimento com a formulação de um problema, exigindo uma simplificação, com uma coleta de dados e uma solução com base nessas atitudes precedentes.

Ainda, de acordo com autor, a obtenção de um modelo não é o mais importante quando a prática é com Modelagem, mas sim o ambiente de investigação em que os alunos se envolvem desde o convite que é realizado. Segundo ele, o engajamento e a reflexão sobre determinados temas favorecem uma formação crítica, quando a configuração desse ambiente sugere um olhar crítico e reflexivo para os dados e o que eles revelam considerando a atividade matemática como prática social.

Explicitamos que outra concepção sobre a Modelagem é tomá-la como alternativa pedagógica. Para os autores que defendem a Modelagem desse modo, ela "pode ser descrita em termos de uma situação inicial (problemática), de uma situação final desejada (que representa uma solução para a situação inicial) e de um conjunto de procedimentos e conceitos necessários para passar da situação inicial para a final" (ALMEIDA e VERTUAN, 2011, p. 21). Paralelamente, podemos entender esses procedimentos como "busca de informações, a identificação e seleção de variáveis, a elaboração de hipóteses, a simplificação, a obtenção de uma representação matemática (modelo matemático), a resolução do problema [...] e a análise da solução que implica numa validação" (ALMEIDA e FERRUZZI, 2009, p. 120-121).

Além dessas, reconhecemos a existência e relevância de outras concepções sobre Modelagem na literatura brasileira, mas como o nosso objetivo não é discutir ou nos amparar em qualquer uma delas, não nos aprofundaremos nesse aspecto. 0 que alertamos é que como foi possível vislumbrarmos a partir dessas concepções que apresentamos, a compreensão sobre 0 que pode ser Modelagem não é a única, aliás, há diferentes concepções que se desvelam na literatura, ancoradas nos propósitos de se fazer Modelagem que são idealizados por diferentes 
autores.

Assim como registramos avanços teóricos e metodológicos acerca da Modelagem, reconhecemos que nesse contexto de pesquisas e práticas convergentes à Educação Matemática, outros pesquisadores têm se destacado com objetos de investigação distintos. Nesse sentido é que destacamos o GeoGebra. Ele começou a ser estruturado como software matemático a partir de 2001, pelo austríaco Markus Hohenwarter, apresentado em sua dissertação de mestrado em 2002.

\begin{abstract}
O GeoGebra foi criado pelo austríaco Markus Hohenwarter em sua dissertação de mestrado (HOHENWARTER, 2002), o GeoGebra (<http://www.geogebra.org>) é um software gratuito desenvolvido para o ensino e aprendizagem da Matemática nos vários níveis de ensino (do básico ao universitário). Por meio de suas múltiplas janelas, - GeoGebra reúne, em um único ambiente, recursos gráficos, numéricos, simbólicos e de programação em Geometria, Aritmética, Álgebra, Funções, Estatística e Probabilidade. Assim, o GeoGebra tem a vantagem didática de apresentar, ao mesmo tempo, representações diferentes de um mesmo objeto que interagem entre si. Existem versões do software para computadores desktop (Windows, Linux e Mac OS), tablets Android e iOS e, mais recentemente, para smartphones Android (BORTOLOSSI, 2016, p. 2).
\end{abstract}

Segundo Bortolossi (2016), atualmente, se um licenciando em Matemática tiver contato com algum software educacional, muito provavelmente será o GeoGebra. Nesse pensamento, a utilização pode ser para o ensino e aprendizagem de vários conteúdos matemáticos, possibilitando sua articulação às diferentes tendências em Educação Matemática, dentre elas, a Modelagem.

Segundo Soares (2017), "esta versatilidade é potencialmente rica para o trabalho com diferentes modelos matemáticos, permitindo a elaboração de diferentes experiências" (p. 4). Um exemplo disso é a utilização do GeoGebra na experimentação que é exigida na prática com Modelagem, podendo favorecer a construção de modelos e interpretações sobre eles. A pesquisa de Pereira e Souza Junior (2018), por exemplo, apresentou resultados relevantes acerca das tecnologias digitais e Modelagem Matemática no Cálculo Diferencial e Integral do Ensino Superior e, nesse contexto, o GeoGebra se expressou como um software que é utilizado em contextos de Modelagem. Pesquisas como as de Araújo (2002) e Lorin (2015), entre outras, também evidenciam a utilização do GeoGebra em contextos de Modelagem.

Essa abordagem da Modelagem com o uso do GeoGebra como agentes que possibilitam uma conexão, parece favorável para abordagem dos conteúdos matemáticos com tecnologia, a fim de atuarem positivamente no processo de aprendizagem, evidenciando, por sua vez, novos caminhos e alternativas para o desenvolvimento da Educação Matemática. É partindo dessas 
reflexões que consideramos a pertinência dessa pesquisa para estudos futuros, pois essas e outras possibilidades de relação entre o GeoGebra e a Modelagem, desveladas em produções ou práticas, pode se revelar nos focos das produções em Modelagem publicadas na CNMEM. Com essa e outras motivações, apresentaremos na seção seguinte, os caminhos percorridos para 0 desenvolvimento dessa investigação.

\section{Aspectos metodológicos da pesquisa}

Entendemos que o pesquisador busca a partir de estudos sistemáticos, melhor conhecer os objetos de pesquisa com o propósito de obter respostas para uma indagação prévia ou que emergiu de suas vivências acadêmicas e profissionais. Para isso, torna-se necessário desenvolver um conjunto de ações que podem aproximá-lo desse objeto, desenvolvendo atitudes que são fundamentais e definidoras nessa atividade. Nesse sentido, sobre a atitude de pesquisar,

\footnotetext{
pode-se definir pesquisa como o procedimento racional e sistemático que tem como objetivo proporcionar respostas aos problemas que são propostos. A pesquisa é requerida quando não se dispõe de informação suficiente para responder ao problema, ou então quando a informação disponivel se encontra em tal estado de desordem que não possa ser adequadamente relacionada ao problema (GIL, 2002, p. 17).
}

Considerando a definição supracitada, compreendemos que interrogar Que focos das produções em Modelagem Matemática que mencionam o GeoGebra, se revelam dos anais da CNMEM (2003-2019)? exige procedimentos sistemáticos de organização e movimentos sucessivos de reflexão, quando almejamos a busca de respostas para essa interrogação. Com essa intencionalidade, buscamos nos anais das edições da CNMEM a partir da III edição datada de 2003, tendo em vista a emergência do GeoGebra em 2002, selecionar que produções faziam menção a esse software.

Como a nossa investigação se desenvolveu a partir da análise de produções já publicadas, ela pode ser considerada como uma pesquisa qualitativa do tipo bibliográfica, já que, em linhas gerais, esse tipo de pesquisa consiste em explorar um objeto de estudo, nesse caso, os focos das produções, "com base em material já elaborado, constituído principalmente de livros e artigos científicos. Embora em quase todos os estudos seja exigido algum tipo de trabalho dessa natureza, há pesquisas desenvolvidas exclusivamente a partir de fontes bibliográficas" (GIL, 2002, p. 44).

É importante salientarmos que a pesquisa bibliográfica, segundo GIL (2002), tem como 
vantagem "permitir ao investigador a cobertura de uma gama de fenômenos muito mais ampla do que aquela que poderia pesquisar diretamente. Essa vantagem torna-se particularmente importante quando o problema de pesquisa requer dados muito dispersos pelo espaço" (p. 45). Mas ela também se mostra como uma pesquisa exploratória, já que se revela, para o primeiro autor, como uma primeira incursão no campo da pesquisa, assim como o ensejo de novas produções e possibilidades de práticas que serão decorrentes desse movimento.

Passando a descrever o processo de investigação, em termos de procedimentos metodológicos, explicitamos que, após o acesso aos materiais das edições da CNMEM, realizamos uma leitura inicial das produções que foram apresentadas nessas edições, no recorte temporal já explicitado, de modo que fosse possível identificar quais delas faziam menção ou abordaram, de algum modo, o GeoGebra. Para tanto, foi realizada uma leitura dos títulos e resumos dos textos. A fim de garantir a abrangência desse levantamento, utilizamos a ferramenta "localizar" do software utilizado para leitura, com o descritor de busca "GeoGebra". Vale ressaltar que foram consideradas nessa busca, todas as modalidades de produções, isto é, Comunicação Científica, Relatos de Experiência e Pôster.

Como resultado dessa busca, obtivemos um total de 14 produções, as quais apresentamos no Quadro 1, a seguir.

Quadro 1: Publicações no CNMEM

\begin{tabular}{|c|c|c|c|}
\hline Edição & Título & Autores & Código \\
\hline XI & $\begin{array}{l}\text { Taxas de analfabetismo e educação a distância: } \\
\text { relato sobre dois modelos obtidos em experiências } \\
\text { com modelagem matemática em um curso de } \\
\text { licenciatura }\end{array}$ & $\begin{array}{l}\text { Lucas Morais Melo } \\
\text { Chrisley Bruno Ribeiro } \\
\text { Camargos }\end{array}$ & P1 \\
\hline$X I$ & $\begin{array}{l}\text { Matemática na exploração de um conceito da Física: } \\
\text { as possibilidades do uso dos softwares Excel e } \\
\text { GeoGebra na obtenção do modelo matemático }\end{array}$ & $\begin{array}{l}\text { Márcia Jussara H. Rehfeldt } \\
\text { Italo Gabriel Neide } \\
\text { Rosilene Inês König } \\
\text { Silvana Emer } \\
\text { Vanessa Brandão de Vargas }\end{array}$ & P2 \\
\hline$X I$ & $\begin{array}{l}\text { Os interpretantes em uma atividade de modelagem } \\
\text { matemática mediada pela tecnologia }\end{array}$ & $\begin{array}{l}\text { Ariely Aparecida Caruzo } \\
\text { Michele Regiane D. Veronez }\end{array}$ & P3 \\
\hline$X I$ & $\begin{array}{l}\text { A modelagem matemática numa experiência } \\
\text { didática com futuros professores da UNEMAT: } \\
\text { aplicação da integral definida de uma variável real }\end{array}$ & $\begin{array}{l}\text { Polyanna Possani da C. } \\
\text { Petry } \\
\text { Kátia Maria de Medeiros }\end{array}$ & P4 \\
\hline
\end{tabular}




\begin{tabular}{|c|c|c|c|}
\hline$X I$ & $\begin{array}{l}\text { Projeto de desenvolvimento de produto em uma } \\
\text { atividade de modelagem matemática }\end{array}$ & $\begin{array}{l}\text { Thiago Fernando Mendes } \\
\text { Kassiana Schmidt Surjus } \\
\text { Adriana Helena Borssoi } \\
\text { Karina Alessandra P. da } \\
\text { Silva }\end{array}$ & P5 \\
\hline$x$ & $\begin{array}{c}\text { "O quanto das mãos não lavamos quando lavamos } \\
\text { as mãos?" - relato de uma atividade de } \\
\text { modelagem matemática }\end{array}$ & $\begin{array}{l}\text { Simone Ribeiro da Silva } \\
\text { Rodolfo Eduardo Vertuan }\end{array}$ & P6 \\
\hline$x$ & $\begin{array}{l}\text { As ações cognitivas e a atividade de modelagem } \\
\text { matemática na aprendizagem de funções }\end{array}$ & $\begin{array}{l}\text { Wasley Antonio Ronchetti } \\
\text { Everton Murilo da V. Olario } \\
\text { Oscar Luiz T. de Rezende } \\
\text { Luciano Lessa Lorenzoni }\end{array}$ & P7 \\
\hline$x$ & $\begin{array}{l}\text { O quanto o protetor solar me protege? Uma } \\
\text { atividade de modelagem matemática. }\end{array}$ & $\begin{array}{c}\text { Elvis Ricardo Viana } \\
\text { Rafael Machado da Silva }\end{array}$ & P8 \\
\hline$X$ & $\begin{array}{c}\text { Estimando a área e o imposto sobre propriedade } \\
\text { territorial rural (ITR) do municipio de Mandaguari: } \\
\text { relato de uma experiência }\end{array}$ & $\begin{array}{c}\text { Tatiane Gilio Torres } \\
\text { Lucilene dos S. Sebastião } \\
\text { Fernando H. do Nascimento } \\
\text { Jair da Silva }\end{array}$ & P9 \\
\hline IX & $\begin{array}{l}\text { O trabalho de projeto digital na educação ambiental: } \\
\text { o carregador fotovoltaico }\end{array}$ & $\begin{array}{l}\text { Arlindo José de S. Júnior } \\
\text { Deive Barbosa Alves } \\
\text { Alex Medeiros Carvalho } \\
\text { Arcenio Menezes da Silva } \\
\text { Jean Carlos Silva }\end{array}$ & P10 \\
\hline VIII & $\begin{array}{l}\text { Modelagem matemática de objetos campeiros: } 0 \\
\text { freio }\end{array}$ & $\begin{array}{l}\text { Herton C. Goerch } \\
\text { Vanilde Bisognin }\end{array}$ & P11 \\
\hline VIII & $\begin{array}{l}\text { Modelagem matemática e a geometria dinâmica: um } \\
\text { estudo das transformações geométricas com o } \\
\text { auxílio do GeoGebra }\end{array}$ & $\begin{array}{l}\text { Liliane R. Refatti } \\
\text { Eleni Bisognin }\end{array}$ & P12 \\
\hline VIII & Um olhar matemático sobre palmitos cortados & Diego Lieban & P13 \\
\hline VIII & $\begin{array}{l}\text { Uma proposta de atividades para semelhanças de } \\
\text { triângulos utilizando o GeoGebra }\end{array}$ & $\begin{array}{l}\text { Pedro Carlos Pereira } \\
\text { Thuany Christine L. de } \\
\text { Azevedo } \\
\text { Robson Mariano da Silva }\end{array}$ & P14 \\
\hline
\end{tabular}

Fonte: Elaboração dos Autores

Após identificação de tais produções, uma leitura criteriosa aconteceu a fim de encontrarmos elementos que expressavam o objetivo dos autores, nas produções. Como a nossa interrogação solicitava os focos das produções, compreendemos que nos debruçarmos apenas sobre os resumos seria suficiente. Contudo, registramos a dificuldade de estabelecer uma 
compreensão mais assertiva, o que nos levou, em alguns momentos, a buscar informações na totalidade dos textos. Esse movimento nos levou à produção de sínteses a respeito das produções, conforme apresentamos no Quadro 2, a seguir.

Quadro 2: Sínteses das produções analisadas

\begin{tabular}{|cl|}
\hline Código & \multicolumn{1}{c|}{ Objetivo } \\
\hline P1 & $\begin{array}{l}\text { Descrever duas experiências de Modelagem Matemática realizadas em sala de aula no decorrer } \\
\text { de uma disciplina ofertada em um curso de Licenciatura em Matemática, envolvendo informática } \\
\text { na Educação Matemática. }\end{array}$ \\
\hline P2 & $\begin{array}{l}\text { Socializar uma prática de Modelagem Matemática, desenvolvida por três professoras } \\
\text { participantes da pesquisa em que foram utilizados os softwares GeoGebra e Excel, bem como } \\
\text { a percepção das docentes da atividade. }\end{array}$
\end{tabular}

Discutir sobre aspectos relacionados à produção de signos (interpretantes) em atividades de

P3 modelagem matemática, mediada pela tecnologia. Para tanto, descrevem uma atividade de Modelagem Matemática que foi desenvolvida apoiada no software GeoGebra.

Buscar um maior envolvimento e interesse por parte dos futuros professores, proporcionar

P4 situações para que compreendam que a Matemática pode ser utilizada em diferentes contextos e, principalmente, contribuir na construção do conhecimento do futuro professor, incentivando0 à pesquisa, com experimentação por meio de algum software livre.

P5 Investigar que conceitos matemáticos podem ser mobilizados no desenvolvimento de uma atividade de modelagem matemática com ferramentas digitais.

Investigar, por meio da Modelagem Matemática, o "quanto da superfície das mãos pode estar

P6 deixando de ser lavada quando lavamos as mãos?". Produzir dados via experimentação e usar o software GeoGebra para trabalhar com eles.

Analisar a aprendizagem de funções em uma atividade de Modelagem Matemática por meio

P7 das ações cognitivas propostas. A atividade de Modelagem Matemática foi problematizada com base na pintura de Leonardo da Vince, o Homem vitruviano.

Apresentar resultados advindos com a adoção da Modelagem Matemática enquanto alternativa

P8 pedagógica promissora ao processo de ensino e aprendizagem do conteúdo matemático e dinamização das aulas de Matemática.

Investigar a temática: cálculo da área e do imposto sobre o território rural da cidade de

P9 Mandaguari. Estudar de forma mais significativa o método de Soma de Riemann, aplicando-o a uma situação real.

Incentivar estudantes que cursavam o $1^{\circ}$ ano do curso de meio ambiente integrado ao Ensino

P10 Médio regular, a interagirem com a Matemática no desenvolvimento de projetos relacionados à educação ambiental. 


\begin{tabular}{|cl|}
\hline P11 & $\begin{array}{l}\text { Trabalhar a modelagem matemática, a partir da realidade de alunos que vivem nas regiões } \\
\text { campeiras do estado do Rio Grande do Sul, e assim desenvolver a modelagem de objetos } \\
\text { utilizados pelos tropeiros, no arreamento da encilha, tendo por base a Educação Matemática } \\
\text { Realista de Hans Freudenthal. }\end{array}$ \\
\hline P12 & $\begin{array}{l}\text { Analisar se as interações propiciadas pelos softwares auxiliam na compreensão dos conceitos } \\
\text { relativos às transformações geométricas e se as ferramentas elou recursos computacionais } \\
\text { auxiliam a aprendizagem dos alunos sobre este conteúdo. }\end{array}$ \\
\hline P13 & $\begin{array}{l}\text { Discutir diferentes possibilidades de abordagens que uma proposta de modelagem pode } \\
\text { apresentar como desdobramentos em uma aula de matemática, desenvolvida com o software } \\
\text { GeoGebra. }\end{array}$ \\
\hline P14 & $\begin{array}{l}\text { Utilizar o GeoGebra com ferramenta educacional para a apresentação de conceitos } \\
\text { geométricos. }\end{array}$ \\
\hline
\end{tabular}

Fonte: Elaboração dos Autores

Após a construção dessas sínteses, efetuamos um movimento de convergência dos sentidos apresentados por cada uma delas, tendo em vista os focos das produções. Esse movimento de convergência deu origem a três núcleos que, para nós, expressam os focos das produções em Modelagem Matemática na CNMEM que mencionam o GeoGebra. No Quadro 3, a seguir, apresentamos uma síntese descritiva sobre o que constitui cada um deles.

Quadro 3: Núcleos, categorias e suas descrições

\begin{tabular}{|c|c|c|c|}
\hline & Núcleo & Síntese & Ocorrência \\
\hline 01 & $\begin{array}{l}\text { Modelagem } \\
\text { Matemática e } \\
\text { GeoGebra na } \\
\text { formação de } \\
\text { professores }\end{array}$ & $\begin{array}{l}\text { O núcleo emergente de estudos na formação de } \\
\text { professores. As pesquisas foram desenvolvidas com a } \\
\text { experimentação por meio da Modelagem Matemática aliada } \\
\text { ao uso de tecnologias, em especial o GeoGebra. }\end{array}$ & $\begin{array}{c}\mathrm{P} 1, \mathrm{P} 4, \mathrm{P} 6, \mathrm{P} 8 \mathrm{e} \\
\mathrm{Pg}\end{array}$ \\
\hline 02 & $\begin{array}{l}\text { Aspectos da } \\
\text { Modelagem } \\
\text { Matemática com } \\
\text { GeoGebra }\end{array}$ & $\begin{array}{l}\text { Esse núcleo se constituiu de produções que tiveram como } \\
\text { foco, a problematização de aspectos relacionados à } \\
\text { Modelagem Matemática com uso direto do GeoGebra na } \\
\text { sua concepção. }\end{array}$ & $\begin{array}{c}\text { P2, P3, P5, P10, } \\
\text { P12 e P14 }\end{array}$ \\
\hline 03 & $\begin{array}{l}\text { Atividades de } \\
\text { Modelagem } \\
\text { Matemática e } \\
\text { GeoGebra }\end{array}$ & $\begin{array}{l}\text { Apresentam propostas de Modelagem Matemática, em que } \\
\text { há indicação ou sugestão do uso de ferramentas } \\
\text { tecnológicas, como o uso de softwares, entre eles, o } \\
\text { GeoGebra. }\end{array}$ & P7, P11 e P13 \\
\hline
\end{tabular}

Fonte: Elaboração dos Autores

Finalizando essa seção compreendemos que a atitude de selecionar, ler, analisar e refletir sobre as produções publicados nas edições da CNMEM se aproxima do Método de Leitura Científica de Cervo e Bervian (1996), caracterizado por movimentos de leitura sincrética, leitura 
analítica e leitura sintética.

Interpretamos, no movimento da pesquisa, que as leituras sincrética e analítica se constituíram, respectivamente, em uma leitura para reconhecimento das produções com a finalidade de selecionarmos o corpus e, na sequência, uma leitura crítica em busca de pôr em evidência as ideias principais acerca do fenômeno de estudo. Após essas duas etapas, avançamos num processo de categorização, o que nos permitiu, a partir da próxima seção, caminhar para o que esses autores intitulam de leitura sintética, isto é, aquela reflexiva e interpretativa que foi reunido nesse movimento.

\section{Descrições e reflexões}

Conforme explicitamos na seção anterior, o movimento de análise efetuado deu abertura a três núcleos, os quais foram constituídos pelos focos das produções selecionadas e analisadas. Os núcleos denominados Núcleo 1 - Modelagem Matemática e GeoGebra na formação de professores; Núcleo 2 - Aspectos da Modelagem Matemática com GeoGebra; e Núcleo 3 Atividades de Modelagem Matemática e GeoGebra, revelam peculiaridades, mas, também, se complementam.

No que diz respeito às produções que compuseram o Núcleo 1-Modelagem Matemática e GeoGebra na formação de professores, elas tiveram como essência o desenvolvimento da pesquisa na formação de professores. De modo geral, essas pesquisas buscaram a experimentação por meio da Modelagem aliada ao uso de tecnologias, em especial GeoGebra, na qual os envolvidos precisaram conhecer e aprender a interagir no software. Algumas das produções expressaram que, com isso, é possível desenvolver novos olhares para a Educação Matemática, a fim de ampliar os modos pelos quais se pode ensinar e aprender Matemática, tendo em vista o papel que o futuro professor de Matemática exerce na sociedade.

Por sua vez, as produções que constituíram o Núcleo 2 - Aspectos da Modelagem Matemática com GeoGebra, evidenciaram o desenvolvimento da Educação Matemática, por meio da Modelagem com uso direto do GeoGebra durante a pesquisa, nota-se que os resultados escritos nessas pesquisas apontam para um aprendizado mais significativo pelos alunos com a junção da Modelagem e o GeoGebra. Nesse sentido, diferente do núcleo anterior, as produções se preocuparam em investigar aspectos inerentes à Modelagem com GeoGebra ou vice-versa. 
Já as pesquisas que deram origem ao Núcleo 3-Atividades de Modelagem Matemática e GeoGebra, apresentaram propostas de Modelagem, em que é indicado ou sugerido o uso de ferramentas tecnológicas, ou seja, softwares como o GeoGebra. Os escritos promoveram uma mostra de resultados que nos levaram a refletir, positivamente, sobre o uso da Modelagem como estratégia de ensino para favorecer o aprendizado dos alunos envolvidos nesse processo, ainda que algumas dificuldades tenham sido constatadas.

Retomando a interrogação que nos iluminou no desenvolvimento dessa pesquisa - Que focos das produções em Modelagem Matemática que mencionam o GeoGebra, se revelam dos anais da CNMEM (2003-2019)? - evidenciamos, portanto, que esses focos expressam alguns significados no contexto dessa pesquisa, da qual nos permitimos discutir alguns deles.

Nossas análises indicam que as produções que compuseram o Núcleo 1 tiveram como interesse refletir sobre o processo de formação do professor quando uma prática com Modelagem pôde ser desenvolvida com GeoGebra, mostrando a importância da introdução da Modelagem e softwares matemáticos na formação inicial do professor. O GeoGebra, por ser livre, gratuito e de manuseio simplificado foi apontado como boa opção para o uso.

À luz das produções analisadas, refletimos que utilizar a Modelagem e o GeoGebra na formação inicial dos professores não é uma garantia de que os futuros professores adotarão esse software e do mesmo modo a Modelagem, nas práticas pedagógicas. Entretanto, refletimos que oportunizar situações para que os futuros professores tenham contato com diferentes recursos é um modo de ampliar as experiências e o seu repertório de conhecimentos e saberes didáticopedagógicos. Mesmo compreendendo que a vivência não garante o empreendimento de práticas - não é uma relação direta - refletimos que, ainda assim, são por meio delas que os futuros professores terão a chance de refletir a respeito dessa possibilidade enviesada pelos pressupostos da Educação Matemática, como um modo para despertar novas compreensões sobre outras formas de ensinar e aprender Matemática.

Para evidenciar essa reflexão, apresentamos o excerto da produção codificada por P1, em que os autores apontaram:

O desenvolvimento de ambos os trabalhos decorreu em um ambiente de aprendizagem permeado por discussões entre os participantes das aulas (alunos e professor) almejando fomentar o conhecimento dos alunos sobre os temas de interesse, além de mostrar como seriam os procedimentos adotados em determinados problemas que teriam como perspectiva para discussão e análise a Modelagem Matemática, promovendo um olhar crítico e matemático sob os problemas. 
De modo convergente, a produção codificada por P4 apresentou um relato cuja experiência teve por objetivo "contribuir na construção do conhecimento dos futuros professores, na perspectiva de proporcionar situações que estimulassem maior envolvimento e o interesse [...], de modo que estes compreendessem as possibilidades da Matemática [...] incentivando-os à pesquisa".

Também houve produções que versaram sobre experiências em contexto de formação inicial como a codificada por P8, tendo como objetivo apresentar resultados advindos com a adoção da Modelagem enquanto alternativa pedagógica. Segundo os autores de P8, o aluno foi "desafiado a propor um tema de seu interesse e após ter vivenciado o primeiro e segundo momentos de familiarização", destacando a Modelagem como promissora aos processos de ensino e de aprendizagem do conteúdo matemático e dinamização das aulas de Matemática, em um curso de formação inicial de professores de Matemática.

Do mesmo modo, a produção P6, elucidou uma experiência com a investigação sobre 0 quanto de superfície das mãos pode estar deixando de ser lavada quando lavamos as mãos, como sendo uma situação de Modelagem que envolveu o uso do GeoGebra na sua exploração. Segundo os autores, a experiência foi realizada "com alunos de uma turma de formação inicial de docentes, que na disciplina de Modelagem Matemática também estudam as possibilidades de um trabalho com a modelagem no que diz respeito ao ensino e à aprendizagem da Matemática na Educação Básica".

Em linhas gerais, destacamos que a preocupação dos autores se volta para a formação do professor, isto é, embora o software apareça articulado ao processo formativo, entendimentos sobre o software no contexto da Modelagem, quando aparecem, emergem como secundário no contexto dos textos, já que o foco é estreitar as reflexões entre experiência e formação, favorecendo interações entre a Modelagem e prática docente.

Esse foco nos chamou a atenção de que em nenhuma dessas produções houve evidências de uso do GeoGebra por professores em exercício, ou seja, as produções indicaram a ocorrência de experiências apenas no âmbito da formação inicial. Para nós, isso pode indicar uma ausência de experiências na formação continuada, sobretudo, a falta de apoio e incentivo aos professores para a realização e comunicação de resultados de experiências exitosas envolvendo Modelagem, GeoGebra, entre outras; e, do mesmo modo, pode indicar um distanciamento de práticas com Modelagem que se reportam ao uso do GeoGebra no contexto da Educação Básica, 
desvinculado de práticas com pesquisa acadêmica.

No que se refere aos materiais analisados e que constituíram o Núcleo 2, evidenciamos que os objetivos das produções admitiram como objeto de investigação aspectos inerentes à relação da Modelagem com o GeoGebra, ou vice-versa, isto é, epistemologicamente, são objetos que expressam uma singularidade entre Modelagem e GeoGebra. Em outras palavras, as produções investigaram aspectos que, para nós, se tornam indissociáveis do ponto de vista investigativo.

Um exemplo que pode ser representativo dessa indissociabilidade é a produção codificada por P3, ao apresentar como objetivo de pesquisa: "aspectos relacionados à produção de signos (interpretantes) em atividades de modelagem matemática, mediada pela tecnologia". Após a análise de uma atividade, os autores expressaram como resultado a compreensão de que "a produção de interpretantes, medida por recursos tecnológicos, pode favorecer com que 0 desenvolvimento de atividades de modelagem matemática possibilite discussões acerca de conceitos matemáticos aliado ao uso de tecnologia (no nosso caso, o GeoGebra)".

A fim de ilustrar outra compreensão que sustenta esse núcleo, a produção codificada como P5 expressa o entendimento dos autores, em que propuseram a investigação sobre "que conceitos matemáticos podem ser mobilizados no desenvolvimento de uma atividade de modelagem matemática com ferramentas digitais", fazendo referência ao uso do GeoGebra. Segundo os autores de P5, "o uso do software GeoGebra possibilitou a construção de alguns elementos geométricos essenciais para que a problemática extramatemática pudesse ser solucionada, como: construção de circunferência (dados centro e raio), determinação de ângulos". Fica evidente que por meio do software, puderam explorar uma situação de Modelagem, favorecendo a mobilização de conceitos matemáticos, sendo possível identificá-los.

Em outras palavras, os focos dessas produções estiveram voltados à investigação de fenômenos que, em sua natureza, Modelagem e GeoGebra se tornam uma unidade. Refletimos que esse tipo de pesquisa potencializa tanto a produção científica, quanto as práticas pedagógicas, pois na medida em que fornecem elementos que tratam das especificidades oriundas dessa simbiose, nos permitem refletir sobre as possibilidades e limites da Modelagem com GeoGebra, desde os elementos que dimensionam essa interação com o software via 0 processo de modelar, conforme expressaram P3 e P5.

Em relação ao Núcleo 3, o foco das produções foi apresentar situações nas quais 0 
GeoGebra emerge como sugestão de ferramenta que pode subsidiar o processo de modelar uma situação. Diferentemente dos anteriores, esse núcleo reuniu produções que revelaram 0 GeoGebra como uma possibilidade para os diferentes contextos de ensino e de aprendizagem. Como evidenciou o objetivo da produção codificada como P7, por exemplo, "analisar a aprendizagem de funções em uma atividade de Modelagem Matemática por meio das ações cognitivas".

Do mesmo modo é possível reconhecermos o uso do GeoGebra em outros ambientes de ensino e de aprendizagem como na formação profissional, revelado pela produção codificada por P11, ao utilizar o GeoGebra na investigação de "contribuições que a Modelagem Matemática de objetos campeiros, relacionados com 0 arreamento da encilha, pode trazer para o ensino e aprendizagem de conceitos matemáticos, para uma turma [...] do ensino médio, do curso Técnico de Agropecuária".

Sustentamos, por meio desses excertos representativos, que o foco dessas produções estiveram em relatar potencialidades de práticas que utilizaram Modelagem e GeoGebra em diferentes contextos. Sobretudo, se considerarmos as relações presentes entre os núcleos, refletimos que esse Núcleo 3 se destaca pelo amplo significado de sua nomenclatura.

Em linhas gerais, concordamos que o revelado pelos núcleos, em alguma medida, se aproximou de reflexões que atestam a viabilidade do uso de "softwares específicos, matemáticos ou não, favorecendo a realização do momento de formulação de problemas, questões, hipóteses e de um modelo, e do momento de interpretação da solução, de avaliação e validação do modelo formulado" (PEREIRA e SOUZA JUNIOR, 2018, p. 9), em contextos cuja prática é com Modelagem. Porém, os núcleos citados guardam suas peculiaridades e, considerando que 0 objetivo da pesquisa é colocar algumas evidências tanto para nós quanto para a comunidade de pesquisadores os focos das produções em Modelagem que mencionam o GeoGebra, compreendemos que essa seção apresentou pelo menos três focos que admitem especificidades, mas que se comunicam para um despertar de saberes pedagógicos, técnicos e matemáticos.

Apresentadas as descrições e algumas reflexões sobre os núcleos, compreendemos que o movimento de investigação empregado nessa pesquisa nos convida a refletir sobre aspectos mais abrangentes. Como possibilidade de estabelecer um diálogo contínuo acerca desse tema, registramos que outros núcleos também podem ser propostos sob outras perspectivas de análise. Diante disso e do que reunimos nessa investigação, passamos às considerações finais. 


\section{Considerações finais}

Considerando a interrogação que nos moveu nessa investigação- Que focos das produções em Modelagem Matemática que mencionam o GeoGebra, se revelam dos anais da CNMEM (2003-2019)? - a pesquisa nos revelou que os focos das produções se articularam em: Modelagem Matemática e GeoGebra na formação de professores; aspectos da Modelagem Matemática com GeoGebra; e atividades de Modelagem Matemática e GeoGebra.

Além da emergência desses focos das produções, refletimos que os significados que eles assumem são de complementaridade, pois ao analisarmos sob uma perspectiva mais ampla, isto é, olharmos de uma posição externa, eles parecem abarcar um movimento de experiênciasreflexões-compreensões-experiências..., sustentado pelas nuances que os tornam como núcleos. A ideia de complementaridade faz sentido na medida em que consideramos a realização de atividades de Modelagem e GeoGebra, seja no contexto da formação de professores (Núcleo 1) ou contexto da Educação Básica (Núcleo 3), e a busca por compreensões de aspectos peculiares da Modelagem com GeoGebra ou vice-versa (Núcleo 2), e a emergência de novas práticas.

Refletimos que, talvez, seja por conta desse movimento que ainda parece estarmos no início de uma caminhada para que juntos, esses três focos, possam promover algumas implicações nas práticas, revelando-se convergentes à Educação Matemática na sala de aula. Essa reflexão decorre, por exemplo, quando consideramos os anos das produções envolvendo 0 GeoGebra, já que a primeira delas, independente do foco, só aparece em 2013. Contudo, é inegável a presença de elementos que referenciam a emergência de saberes pedagógicos, técnicos e matemáticos, no desenvolver de reflexões teórico-práticas inerentes às produções analisadas.

Os núcleos emergentes revelam esses saberes ao dirigirem-se para a formação de professores, indicando os pedagógicos na medida em que se destaca o aspecto formativo das produções, enaltecendo a formação docente via as experiências envolvendo Modelagem e 0 GeoGebra; para saberes técnicos e matemáticos, ressaltando o saberes técnicos-operacionais exigidos pelo manuseio do software nas experiências que são investigadas, as quais exigem conhecimentos e saberes matemáticos. Talvez, uma reflexão sobre esses saberes possa se configurar numa agenda de pesquisa, quando interpretamos os saberes matemáticos como aspectos estritamente técnicos para o desenvolvimento de uma modelagem valendo-se de um software. 
Também chamamos a atenção para os aspectos intrínsecos às práticas com Modelagem, como a de uma prática interdisciplinar revelada na produção codificada como P2, cujo foco é o relato de uma experiência de Modelagem com GeoGebra no estudo de tópicos de Física. É interessante destacar o espectro de abrangência dessa ferramenta, o GeoGebra, no estudo e compreensão de temas interdisciplinares. 0 uso do software pode favorecer a compreensão de fenômenos de outras áreas, envolvendo situações extramatemática, bem como auxiliar na definição de variáveis, estratégias e definição de um modelo, conforme relatado na pesquisa. Além disso, vale ressaltar que é da natureza da Modelagem investigar temas com referência na realidade, portanto, uma abordagem que pode ser mais bem explorada sobre usos, limites e possibilidades de investigações de temas inerentes a outras áreas do conhecimento por meio da Modelagem com GeoGebra.

Entendemos que aumentam as chances de práticas como essas serem empreendidas, quando os professores já experienciaram práticas formativas para que utilizem de estratégias como a Modelagem Matemática e o GeoGebra nas suas aulas. Nesse sentido é que alertamos que a ausência de práticas em contextos de formação continuada, fazendo referência ao Núcleo 1, pode ser um convite para a comunidade de pesquisadores em Modelagem a refletir sobre novos projetos de formação continuada, envolvendo o software GeoGebra, para o empreendimento de outras práticas. Alertamos que essa afirmação não invalida os argumentos de que práticas isoladas aconteçam em contextos de formação continuada.

Salientamos que esse trabalho tem a sua importância revelada por meio da análise das publicações apresentadas nas edições da CNMEM envolvendo o GeoGebra, na qual se mostra um evento de prestígio, idealizado pela comunidade de pesquisadores em Modelagem. Foi possível conhecer as relações entre a Modelagem e o GeoGebra abordadas nas produções, segundo os seus focos. Elas revelam o que há de produção sobre esses temas no escopo da produção da CNMEM e este artigo oferece reflexões pertinentes para professores e pesquisadores que intencionam promover experiências sejam elas voltadas, para a utilização de softwares matemáticos na formação inicial de professores, na estruturação de projetos de formação continuada com a Modelagem e/ou (com) GeoGebra, no uso da Modelagem com o software GeoGebra nos diferentes níveis de ensino, ou outras ideias que se articulam à investigação e prática envolvendo Modelagem, GeoGebra, e Educação Matemática.

Dito de outro modo, os focos das produções nos trouxeram conhecimentos e saberes 
intrínsecos à temática, os quais podem ser abordados por novas pesquisas e ser inspiração para novas experiências. Uma combinação de Modelagem com GeoGebra, por trazer um dinamismo às experiências pedagógicas, pode ensejar novos estudos e uma busca contínua pelo conhecimento de um alinhamento da Modelagem ao GeoGebra, expandindo novos olhares e novas ações aos pesquisadores e professores, agregado-se às reflexões que apresentamos.

Temos a consciência de que as discussões sobre o tema abordado nesse texto são amplas, inclusive, abrindo outras discussões nas possíveis relações estabelecidas entres os núcleos emergentes. Portanto, para encerrarmos o escrito e não as ideias, esclarecemos que a nossa pretensão em investigar por meio desse levantamento foi conhecer sobre as produções apresentadas à CNMEM com menção ao GeoGebra, não só de forma a subsidiar as nossas próximas experiências com o projeto em desenvolvimento.

Temos a clareza de que o empreendimento de estudos como esse que apresentamos se aproximam daqueles sugeridos como metaestudo, metanálise, ou estado do conhecimento, ainda que eles possuam especificidades na conjuntura acadêmica. Assim como estudos dessa natureza, entendemos que essa pesquisa se mostra como uma oportunidade para que os iniciantes com essa temática possam refletir sobre objetivos de pesquisas envolvendo Modelagem e GeoGebra e, transitivamente, contribuir com reflexões de jovens e experientes pesquisadores da área.

\section{Referências}

ALMEIDA, Lourdes Maria Werle de; FERRUZZI, Elaine Cristina. Uma aproximação socioepistemológica para a modelagem matemática. Alexandria, Florianópolis, v. 2, n. 2, p. 117134, jul./dez. 2009.

ALMEIDA, Lourdes Maria Werle de; VERTUAN, Rodolfo Eduardo. Discussões sobre "como fazer" modelagem matemática na sala de aula. In: ALMEIDA, Lourdes Maria Werle de; ARAÚJO, Jussara de Loyola; BISOGNIN, Eleni. (Org.). Práticas de modelagem matemática na Educação Matemática: relatos de experiências e propostas pedagógicas. Londrina: EdUEL, 2011, p. 19-43.

ARAÚJO, Jussara de Loyola. Cálculo, tecnologias e modelagem matemática: as discussões dos alunos. 2002. 173f. Tese (Doutorado em Educação Matemática) — Instituto de Geociências e Ciências Exatas. Universidade Estadual Paulista. Rio Claro.

BARBOSA, Jonei Cerqueira. Modelagem matemática e os professores: a questão da formação. Bolema, Rio Claro, v. 14, n. 15, p. 5-23, 2001.

BARBOSA, Jonei Cerqueira. Sobre a pesquisa em Modelagem Matemática no Brasil. In: CONFERÊNCIA NACIONAL SOBRE MODELAGEM NA EDUCAÇÃO MATEMÁTICA, 5, 2007, Ouro Preto. Anais da V CNMEM. Ouro Preto: UFOP, 2007, p. 82-103. 
BIEMBENGUT, Maria Salett. 30 Anos de Modelagem Matemática na Educação Brasileira: das propostas primeiras às propostas atuais. Alexandria, Florianópolis, v. 2, n. 2, p. 7-32, jul./dez. 2009.

BORTOLOSSI, Humberto José. O uso do software gratuito GeoGebra no ensino e na aprendizagem de Estatística e Probabilidade. Vidya, Santa Maria, v. 36, n. 2, p. 429-440, jul./dez., 2016.

BURAK, Dionísio. Modelagem matemática: ações e interações no processo de ensino aprendizagem. 1992. 460f. Tese (Doutorado em Educação) - Faculdade de Educação. Universidade Estadual de Campinas. Campinas.

CERVO, Amando Luiz; BERVIAN, Pedro Alcino. Metodologia científica. São Paulo: Makron Books, 1996.

GIL, Antônio Carlos. Como elaborar projetos de pesquisa. 4. ed. São Paulo: Atlas, 2002.

KLÜBER, Tiago Emanuel; BURAK, Dionisio. Concepções de modelagem matemática: contribuições teóricas. Educação Matemática Pesquisa, São Paulo, v. 10, n. 1, p. 17-34, jan./jul. 2008.

LORIN, Ana Paula Zanim. Competências dos alunos em atividades de Modelagem Matemática. 2015. 164f. Dissertação (Mestrado em Ensino de Ciências e Educação Matemática) - Centro de Ciências Exatas. Universidade Estadual de Londrina. Londrina.

MEYER, João Frederico da Costa de Azevedo; CALDEIRA, Ademir Donizeti; MALHEIROS, Ana Paula dos Santos. Modelagem em Educação Matemática. Belo Horizonte: Autêntica, 2011.

PEREIRA, Giselle Moraes Resende. SOUZA JUNIOR, Arlindo José de. Pesquisas brasileiras sobre Tecnologias Digitais e Modelagem Matemática no Cálculo Diferencial e Integra do Ensino Superior. In: SEMINÁRIO INTERNACIONAL DE PESQUISA EM EDUCAÇÃO MATEMÁTICA, 7, 2018, Foz do Iguaçu. Anais do VII SIPEM. Foz do Iguaçu: SBEM, 2018, p. 1-12.

ROMANOWSKI, Joana Paulin; ENS, Romilda Teodora. As pesquisas denominadas do tipo "Estado da Arte" em Educação. Diálogo Educacional, Curitiba, v. 6, n. 19, p. 37-50, set./dez., 2006.

SOARES, Débora da Silva. Modelagem Matemática com ouso do software GeoGebra. In: CONFERÊNCIA NACIONAL SOBRE MODELAGEM NA EDUCAÇÃO MATEMÁTICA, 10, 2017, Maringá. Anais da X CNMEM - Modelagem Matemática na Educação Matemática e a Escola Brasileira: Histórias, atitudes e projeções. Maringá: UEM, 2017, p. 1-9.

TAMBARUSSI, Carla Melli; KLÜBER, Tiago Emanuel. A pesquisa em Modelagem Matemática no âmbito da Educação Matemática brasileira: um olhar epistemológico. Revista Paranaense de Educação Matemática, Campo Mourão, v. 3, n. 5, p. 180-199, jul./dez. 2014. 